\title{
The Evaluation of Bioremediation Potential of a Yeast Collection Isolated from Composting
}

\author{
Bianca Trama*, João Daniel Santos Fernandes*, Geórgia Labuto, \\ Júlio Cézar Franco de Oliveira, Cristina Viana-Niero, Renata C. Pascon, \\ Marcelo A. Vallim" \\ Departamento de Ciências Biológicas-Universidade Federal de São Paulo, Diadema, São Paulo, Brasil \\ Email: ${ }^{\#}$ marcelo.vallim@gmail.com
}

Received 22 June 2014; revised 26 July 2014; accepted 30 August 2014

Copyright (C) 2014 by authors and Scientific Research Publishing Inc. This work is licensed under the Creative Commons Attribution International License (CC BY). http://creativecommons.org/licenses/by/4.0/

(c) () D Den Access

\begin{abstract}
The influence of xenobiotic compounds on environment and on living organisms has been reported as an imminent public health problem. Among them we can list the contamination by Alkanes present in petroleum, hydrocarbons and organic contaminant substances from industrial effluents. Also, heavy metals are of particular interest because of their persistence in the environment contaminating the food webs. Among the innovative solutions for treatment of contaminated water and soil is the use of biological materials like living or dead microorganisms. Yeasts exhibit the ability to adapt to extreme condition such as temperature, $\mathrm{pH}$ and levels of organic and inorganic contaminants that make them a potential material to be used to remediate contaminated environment application. The goal of this work was to search for yeast isolates capable to use n-hexadecane (alkane hydrocarbon) as a primary carbon source and for those able to tolerate high concentration of lead $(\mathrm{Pb})$ within a collection of 90 isolates obtained from the São Paulo Zoo composting system. The isolated yeast strains were identified by mass spectrometry (MALDI-TOF-MS) and by sequencing of the ribosomal DNA (18S and D1/D2) conserved regions. We found that the collection bares 23 isolates capable of utilizing $n$-hexadecane and one which is able to tolerate high concentration of lead $(\mathrm{Pb})$ with a high biosorption index compared to the reference yeast strains (BY4742, PE-2, CAT-1 and BG-1). These results confirm the initial hypothesis that the São Paulo Zoo composting is the source for diverse yeasts species with biotechnological application potential.
\end{abstract}

\section{Keywords}

Biosorption, Lead, Yeast, Trichosporon montevideense, Saccharomyces cerevisiae

\footnotetext{
*Both authors contributed equally to this work.

"Corresponding author.
}

How to cite this paper: Trama, B., Fernandes, J.D.S., Labuto, G., de Oliveira, J.C.F., Viana-Niero, C., Pascon, R.C. and Vallim, M.A. (2014) The Evaluation of Bioremediation Potential of a Yeast Collection Isolated from Composting. Advances in Microbiology, 4, 796-807. http://dx.doi.org/10.4236/aim.2014.412088 


\section{Introduction}

The influence of xenobiotic compounds on environment and on living organisms has been reported as an issue of concern and has been listed as one of 40 priorities for conservation policy and management [1]. Alkanes present in petroleum, hydrocarbons and organic contaminant substances from industrial effluents are increasingly being disposed into the soil and water leading to pollution [2]. Metals as contaminants are also of particular interest because of their liability, which make their persistence possible in the environment with the possibility of interconversion between species, favoring migration among physic compartments and food webs [3].

Lead is known by mankind for many years and it has been employed in several processes ever since. The anthropogenic $\mathrm{Pb}$ input in the environment decreased in the last decades after banishing its application as a gasoline additive in many countries. However, it is still widely applied in industries of paper, plastic, ceramic, automotive, semiconductors and pigments [4], and as a consequence $\mathrm{Pb}$ is still introduced in the environment nowadays [5].

Moreira et al. [6] reported several health problems related to $\mathrm{Pb}$ contamination, which may include neurological and hematological abnormalities, endocrine disruption, fetal development, and it may interfere with processes such as reproduction, renal, hepatics, gastrointestinal and cardiovascular functions, besides its carcinogenic effects. Therefore, it is urgency to develop new technologies for the treatment and recovery of $\mathrm{Pb}$ from industrial waste before its discard and disposal. Among the many biotechnology processes available to remediate the contamination by heavy metals, the use of microorganisms capable of accumulating these metals and metal species has gained prominence either by bioremediation through bioaccumulation or by the recovery of metals for a new application, converting an environmental liability into an economic asset, such as in biometallurgical process [7]-[9].

Different kinds of organisms have been successfully used for bioremediation, from plants to microbes (for reviews see [10]-[12]). The microbial metabolic diversity and versatility is part of the reason why they are suitable as agents for remediation among many living organisms. In general bacteria, fungi and yeast are able to assimilate complex and recalcitrant substrates as carbon and nitrogen sources, as well as to conduct biotransformation of recalcitrant substances that would accumulate in the environment. Metal bioaccumulation can also be achieved by the action of algae, plants, bacteria and fungi. Dursun et al. [13] obtained a maximum Pb uptake of $34.4 \mathrm{mg} \cdot \mathrm{g}^{-1}$ by Aspergillus niger. Li et al. [14] evaluated Cd accumulation during the Zygosaccharomyces rouxii and Saccharomyces cerevisiae growth reaching 94\% accumulation of Cd. Therefore, the prospection and evaluation of tolerant microorganisms capable of xenobiotic compound assimilation and metal accumulation have great interest for bioremediation.

Many microorganisms isolated from contaminated soil, waste waters, compost and extreme environments have been proven useful for bioremediation [15]-[18]. Their success to survive in such a harsh environment can be attributed to metabolic possibilities allowing microbes to explore, detoxify and survive in exotic and complex substrates. In this work, organic composting waste from São Paulo Zoo Park in Brazil, which is known as a rich source of microbial diversity [19]-[22] was used as the starting material for isolation of yeast strains capable to use hydrocarbon as main carbon source and tolerate and accumulate heavy metals. Two yeast collections containing 90 isolates were assembled and identified by MALDI-TOF biotyping and ribosomal DNA sequence. Among these, several Ascomycetes and Basidiomycetes able to use n-hexadecane as sole carbon source were found. Also, a yeast strain was identified which is highly tolerant to $\mathrm{Pb}$ and capable of uptaking and accumulating high concentration of this hazardous heavy metal. In this paper, the biotechnological potential of yeast isolates from São Paulo Zoo Park Compost will be revealed and emphasis will be given to the Pb bioaccumulation capabilities.

\section{Material and Methods}

\subsection{Strains and Growth Conditions}

General yeast medium was YPD (Yeast extract 5 g/L, Peptone 10 g/L, Dextrose 20 g/L, HCl 1 N 5 mL/L, agar $20 \mathrm{~g} / \mathrm{L}$ ). S. cerevisiae reference strain (S288c background) used in this work is BY4742 acquired from Genetics Research, industrial strains (PE-2, CAT-1 and BG-1) were a gift from Dr. Luis Carlos Basso [23].

\subsection{Yeast Isolation}

Samples from São Paulo Zoo Organic Compost Unit (UPCO) were collected from different composting cells 
according to the protocol published before [19] [20] [22]. In brief, samples were diluted in $0.9 \% \mathrm{NaCl}$, homogenized and let settle at room temperature for 2 hours. Serial dilutions of the supernatant $\left(10^{-1}\right.$ to $\left.10^{-8}\right)$ were platted on the following fungal enrichment media: Potato-Dextrose Agar, Czapek Dox, Malt Extract, ISP2, Sabouraud-Dextrose Agar and YEPD, all supplemented with $25 \mu \mathrm{g} / \mathrm{mL}$ chloramphenicol. Growth was observed every 24 hours during 15 days. Yeast-like and filamentous colonies were inspected under the stereomicroscope, isolates were purified to single colonies and analyzed for yeast-like micromorphology and stored in $15 \%$ glycerol at $-80^{\circ} \mathrm{C}$ in ultra freezer.

\subsection{Yeast Identification by MALDI-TOF}

MALDI-TOF spectrometry and Biotyper software were used for microbial identification [24]. Ethanol/formic acid extraction method was applied for each isolate as suggested by Bruker Daltonics. In brief, plates containing fresh colonies were used as source of cells which were scraped, transferred to microtubes and diluted in $300 \mu \mathrm{L}$ of sterile water. Absolute ethanol $(900 \mu \mathrm{L})$ was added, mixed, and cells were centrifuged at 10,000 g for 2 minutes at room temperature $\left(25^{\circ} \mathrm{C}\right)$. The supernatant was discarded and the pellet air dried. The dry pellets were mixed thoroughly with $50 \mu \mathrm{L} \mathrm{70 \%} \mathrm{formic} \mathrm{acid} \mathrm{(Merck,} \mathrm{USA)} \mathrm{and} 50 \mu \mathrm{L}$ acetonitrile (Merck, USA). The suspension was centrifuged at $10,000 \mathrm{~g}$ for 2 minutes, and $1 \mu \mathrm{L}$ of the supernatant was placed on Micro Scout Plate (MSP) 96 polished steel target (Bruker Daltonics $\mathrm{GmbH}$, Germany) and dried at room temperature $\left(25^{\circ} \mathrm{C}\right)$. Each sample was overlaid with $1 \mu \mathrm{L}$ of the matrix solution which consisted of a saturated solution of a-cyano-4-hydroxy-cinnamic acid (Sigma, USA) in 50\% acetonitrile-2.5\% trifluoroacetic (Sigma, USA), and the matrix/ sample was co-crystallized by air drying at room temperature $\left(25^{\circ} \mathrm{C}\right)$. Measurements were performed with Microflex LT mass spectrometer (Bruker Daltonics) using FlexControl software (version 3.0, Bruker Daltonics). Positive linear mode was used to record Spectra (laser frequency, $20 \mathrm{~Hz}$; ion source 1 voltage, $20 \mathrm{kV}$; ion source 2 voltage, $18.6 \mathrm{kV}$; lens voltage, $7.5 \mathrm{kV}$; mass range, 2000 to 20,000 Da). For each spectrum, 240 shots in 50shot steps from different positions of the target spot (automatic mode) were collected and analyzed. Escherichia coli ribosomal proteins were used as internal calibration. The raw spectra were imported into the Biotyper software (version 2.0, Bruker Daltonics), processed by standard pattern matching with default settings, and the results reported in a ranking table. Outcomes of the pattern-matching process were expressed as proposed by MALDI-TOF Biotyper (MT) manufacturer with ID scores ranging from 0 to 3 . Scores $<1.70$ were considered not to have a generated reliable ID; a score of $1.7 \leq \mathrm{ID} \geq 1.9$ was considered ID to genus, and a score $>1.9$ was used for reliable species ID according to the software manufacturer (Bruker Daltonics).

\subsection{Yeast Identification by Ribosomal DNA Sequencing}

Yeast genomic DNA was extracted from $3 \mathrm{~mL}$ overnight liquid cultures according to the protocol described by Hoffman and Winston [25]. Small Subunit RNA (18S) and intergenic region D1-D2 were amplified by PCR (polymerase chain reaction), using $1 \mathrm{U}$ Taq Polymerase (New England Biolabs, USA), $1 \times$ Buffer (10 mM Tris-HCl, $50 \mathrm{mM} \mathrm{KCl}, \mathrm{pH}$ 8.3), $2 \mathrm{mM} \mathrm{MgCl}_{2}, 200 \mu \mathrm{M}$ dNTP's (Fermentas, Finland), $0.2 \mu \mathrm{M}$ of each primer (IDT, USA). Table 1 describes the primers used. Amplification condition: 1 cycle $94^{\circ} \mathrm{C}$ for 5 minutes, 35 cycles: denaturing at $94^{\circ} \mathrm{C}$ for 30 seconds, primers annealing at $54^{\circ} \mathrm{C}$ for 30 seconds, and extension at $72^{\circ} \mathrm{C}$ for 1 minute, a final extension of $72^{\circ} \mathrm{C}$ for 7 minutes. Single-band amplicons were purified with PCR Clean up Kit (Axigen Scientific, USA) and double stranded sequenced with BigDye Terminator (Applied Biosystems, USA) according to the manufacturer's instructions. The sequences were aligned using SeqMan module of software Lasergene

Table 1. Primers used for 18S and D1-D2 ribosomal DNA sequencing.

\begin{tabular}{cccccc}
\hline Primer & Sequence & Region & Amplicon & $\begin{array}{c}\text { Annealing } \\
\text { temperature }\end{array}$ & Reference \\
\hline PRCP007 & TTAGCATGGAATAATRRAATAGGA & $18 \mathrm{~S}$ & $760 \mathrm{bp}$ & $60^{\circ} \mathrm{C}$ & \\
PRCP008 & ATTGCAATGCYCTATCCCCA & $18 \mathrm{~S}$ & $760 \mathrm{bp}$ & $58^{\circ} \mathrm{C}$ & Valente et al. [53] \\
PRCP039 & GCATATCAATAAGCGGAGGAAAAG & D1-D2 (25S) & $600 \mathrm{bp}$ & $68^{\circ} \mathrm{C}$ & $60^{\circ} \mathrm{C}$ \\
PRCP040 & GGTCCGTGTTTCAAGACGG & D1-D2 (25S) & $600 \mathrm{bp}$ & & \\
\hline
\end{tabular}


(DNAStar, USA) and blasted against Genebank. Identification at species level was considered for sequence similarities above $97 \%$.

\subsection{Yeast Assimilation of $\mathrm{N}$-Hexadecane as Carbon Source}

N-hexadecane assay was performed in 96 wells plates containing YNB with ammonium sulphate and amino acids supplemented with $1 \%$ of n-hexadecane (Sigma) as the main carbon source, in a final volume of $100 \mu \mathrm{L}$. Each well was inoculated with $10 \mu \mathrm{L}$ of fresh culture grown overnight in YPD $\left(30^{\circ} \mathrm{C}, 150 \mathrm{rpm}\right.$ rotation). The wells were stained with $10 \mu \mathrm{g} / \mathrm{mL}$ MTT (Methylthiazolyldiphenyl-tetrazolium bromide, Sigma) and incubated with agitation (100 rpm) for 2 hours at $30^{\circ} \mathrm{C}$. Negative control was considered medium without inoculum or the lack of E. coli growth and the positive control was USM 537, which is a bacterial isolate that assimilates n-hexadecane as sole carbon source [20]. Yeast isolates considered positive for n-hexadecane assimilation are those that turned purple after incubation period of 2 hours as described above. All assays were made in triplicates.

\subsection{Disk Diffusion Assay}

Disk diffusion method was employed as a sensitivity screening test to find isolates tolerant to $\mathrm{Pb}$ [26]. Briefly: each isolate was grown overnight in $5 \mathrm{~mL}$ of YEPD, at $30^{\circ} \mathrm{C}$ with agitation $(150 \mathrm{rpm})$. Each culture was diluted in sterile $0.9 \% \mathrm{NaCl}(1: 10)$ and $100 \mu \mathrm{L}$ aliquots were spread evenly onto YPD plates. Filter paper disks $(0.5 \mathrm{~cm})$ were previously soaked with $0.5,1.0,2.5$ and $5.0 \mathrm{mg}$ of $\mathrm{Pb}^{2+}$. Positive control was performed with the same type of disks impregnated with $200 \mu \mathrm{g}$ of fluconazole and negative control with water. The disks were laid on inoculated plates, which were incubated at $30^{\circ} \mathrm{C}$ for 48 hours and plates were inspected every 12 hours. All experiments were made in triplicates.

The contact of $\mathrm{Pb}$ with the solid YPD formed a precipitate observed between the filter paper discs and the growing colony. Inhibitory concentration was considered when a clear zone (no growth) was observed around the edge of the disk. Tolerance was identified by no clear zone around the paper disk, there is, colony growth met edge of the paper disk soaked with different concentrations of $\mathrm{Pb}$.

\subsection{Pb Uptake by Yeast Cells}

$\mathrm{Pb}$ uptake experiments were performed with fresh yeast cells prepared as follow: $500 \mathrm{~mL}$ of YPD was inoculated with $5 \mathrm{~mL}$ of fresh culture grown overnight in YPD and incubated $30^{\circ} \mathrm{C}, 16$ hours with agitation $(150 \mathrm{rpm})$. The cells were washed three times in sterile $0.9 \% \mathrm{NaCl}$ solution by centrifugation ( $4000 \mathrm{rpm}, 10$ minutes at $10^{\circ} \mathrm{C}$ ). After the last wash, cells were brought to suspension in $\mathrm{NaCl}(0.9 \%)$ and divided in aliquots of the same volume for further $\mathrm{Pb}$ uptake experiments.

\subsection{Yeast Inactivation by UV Irradiation}

Aliquots of fresh yeast cells prepared as described above were placed in Petri dishes $(150 \times 15 \mathrm{~mm})$ and exposed to UV irradiation (30 W lamp) at $20 \mathrm{~cm}$ distance for $0,10,20,30$, and 50 minutes under constant shaking (150 $\mathrm{rpm})$. Samples from each irradiation exposure time were serial diluted and spotted on YPD (5 $\mu \mathrm{L}$ of the dilutions: $10^{-1}, 10^{-2}, 10^{-3}, 10^{-4}, 10^{-5}$ and $10^{-6}$ ) and incubated at $30^{\circ} \mathrm{C}$ for 48 hours. Colonies counts were conducted to evaluate the cell viability and identify the time point suitable to complete inactivation. Cells were maintained in the dark during and after irradiation in order to avoid DNA repair mechanism activation.

\subsection{Pb Quantification}

Viable and UV inactivated cells were suspended in $5 \mathrm{~mL}$ of a solution containing $\mathrm{Pb}\left(5000 \mathrm{mg} \cdot \mathrm{L}^{-1}\right)$ and placed in an orbital shaker $(150 \mathrm{rpm})$ at room temperature for 1,5 and 10 minutes. Cells were harvested by centrifugation (2 minutes at $4000 \mathrm{rpm}$ ) and the supernatants were discharged. The pellets were frozen in dry ice, lyophilized for 24 hours and stored at room temperature. In order to quantify $\mathrm{Pb}$ adsorbed $0.1 \mathrm{~g}$ of lyophilized cells

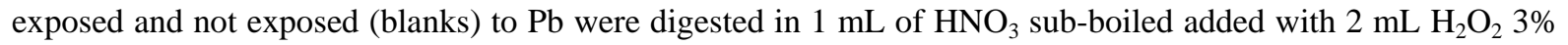
$\mathrm{v} / \mathrm{v}$ in a microwave oven ( $2 \mathrm{~min}$ at $750 \mathrm{~W}, 2 \mathrm{~min} 0 \mathrm{~W}, 18 \mathrm{~min}$ at $800 \mathrm{~W}, 6 \mathrm{~min}$ at $0 \mathrm{~W}$ and $30 \mathrm{~min}$ of cooling). A SpectrAA-800 GFAAS (Varian, Mulgrave Victoria, Australia) equipped with deuterium lamp as background 
corrector and a GTA 96 auto sampler was used for Pb determination performed at $2833 \mathrm{~nm}$, with a slit-width 0.2 $\mathrm{nm}$. Pyrolytically coated graphite tubes without chemical modifier and L'vov platform (Varian, Mulgrave Victoria, Australia) were used. A volume of $20 \mu \mathrm{L}$ of sample was injected in the GFAAS by the auto sampler after appropriated dilutions. The results were obtained in peak areas and the quantification was performed using analytical curves. The $\mathrm{Pb}$ pyrolysis and atomization temperatures were set as $700^{\circ} \mathrm{C}$ and $1000^{\circ} \mathrm{C}$, respectively [27]. The ANOVA statistical analysis followed by Student's t-test was applied to verify statistical difference between averages of the treatments.

\section{Results and Discussion}

\subsection{Yeast Collection}

São Paulo Zoo Compost Unit has proven to be a source of relevant microorganisms for biotechnological applications [19]-[22]. This compost is the result of microbial transformation of excreta from animals coming from all around the world and the waste of Atlantic forest vegetation into fertilizer [19]. The zoo compost gathers great unexplored microbiology diversity. Our previous reports used metagenomic approach to show the bacterial community structure present in this substrate [21] also, several bacterial strains from this exotic environment have been appointed as potential biotechnology tools [20] [22]. However, the diversity of yeast and filamentous fungi has never been described in São Paulo Zoo Park Compost. The yeast cells are known as metabolic versatile [28] [29] also yeast cell wall is well known for its ability to bind metals [9] [30]-[33], therefore, they may have several potential applications [34]. In this study we assembled a yeast collection isolated from compost aiming to explore its potential as bioremediation agents. A total of 90 strains were isolated and protein profiles were generated by MALDI-TOF spectrum. The Biotyper software was used to compare these profiles with those deposited at the Brucker Daltonics database. As positive controls E. coli, USM 470 and a C. neoformans serotype A (var. grubbii) laboratory strain H99 were added to each MALDI-TOF plate. Scores higher than 1.9 were used to attribute genus and species to each isolate. Out of 90 isolates, 35 generated novel profiles, for which similarities were not found at Brucker Daltonics database. These isolates were submitted to ribosomal DNA sequence at 18 or $25 \mathrm{~S}$ regions. Table 2 describes the consolidated results of yeast identification by MALDI-TOF and DNA sequence. The majority of yeast strains isolated belongs to the genus Candida (57\%), followed by Pichia (17\%) and Trichosporon sp. (6.5\%). The genus Candida was the most diverse (9 different species), followed by Pichia (5 species) as described in Table 2. Also, the Ascomycete (Candida, Pichia, Debaryomyces, Hanseniaspora, Meyerozyma and Stephanoascus spp.) predominated over the Basidiomycete (Trichosporon, Rhodotorula and Cryptococcus) which is consistent with the literature considering that the Ascomycota phylum is larger than Basidiomycota [35] [36]. Fungi are known as saprophytic microbes that decompose a large range of organic matter, even the most complex and recalcitrant as lignocelluloses, especially the Basidiomycete are well known for this ability (for review see [37]). The diverse metabolic arsenal present among the yeasts and their easy and simple manipulation reflect on their applicability as bioremediation agents [34]. In this work we inquired whether our yeast collection from São Paulo Zoo Compost has isolates suitable to bioremediation applications. To address this question we searched the collection for two important phenotypes associated to bioremeditation: ability to assimilate n-hexadecane, a model xenobiotic considered a recalcitrant Carbon source [38] and tolerance to high levels of $\mathrm{Pb}$, an important heavy metal that contaminates the environment.

\section{2. n-Hexadecane Assimilation by Yeasts}

Our previous results demonstrated that several bacteria from compost are able to metabolize n-hexadecane and therefore, have potential for bioremediation [20]. We used the same method (broth micro assay with n-hexadecane as main carbon source) to screen 90 isolates and identified 23 yeast capable of growth in $1 \%$ n-hexadecane (Table 3). Among these isolates, $18 \%$ and $62.5 \%$ belong to phylum Ascomycota and Basidiomycota, respectively, suggesting this phenotype is more often found in the later phylum. This observation is in accordance with the literature, since Basidiomycetes are known to consume complex carbon sources efficiently [37] [38].

The literature report several uses of Ascomycetes in bioremeditation. C. catenulata is able to assimilate oil from contaminated soil [15]. In this report $84 \%$ of hydrocarbon was removed from oil by composting it with $C$. catenulata. Other reports, mention the use C. krusei and C. rugosa, Pichia gilliermondii and Meyerozyma guil liermondii in biotransformation of pigments, lipase sources, degradation of polycyclic aromatic compounds and 
Table 2. Taxonomic identification of yeasts isolated from São Paulo Zoo Compost.

\begin{tabular}{|c|c|c|c|}
\hline Code & Taxonomic identification & MALDI-TOF-MS score & DNA sequence similarity \\
\hline USM 384 & Candida tropicalis & 2.298 & - \\
\hline ULP 385 & Pichia kluyveri & 2.050 & $100 \%$ \\
\hline ULP 387 & Pichia kluyveri & 2.423 & $100 \%$ \\
\hline ULP 388 & Candida krusei & 2.388 & - \\
\hline ULP 389 & Candida tropicalis & 2.177 & - \\
\hline ULP 390 & Candida tropicalis & 2.232 & - \\
\hline ULP 391 & Candida krusei & 2.162 & - \\
\hline ULP 392 & Candida krusei & 2.334 & - \\
\hline ULP 393 & Pichia kluyveri & 2.547 & $100 \%$ \\
\hline ULP 394 & Pichia kluyveri & - & $100 \%$ \\
\hline ULP 395 & Candida krusei & 2.204 & - \\
\hline ULP 398 & Pichia guilliermondii & - & $99 \%$ \\
\hline USM 399 & Debaryomyces hansenii & - & $100 \%$ \\
\hline USM 400 & Pichia guilliermondii & 2.720 & $99 \%$ \\
\hline USM 402 & Candida tropicalis & 2.225 & - \\
\hline USM 404 & Debaryomyces hansenii & - & $100 \%$ \\
\hline USM 405 & Debaryomyces hansenii & - & $98 \%$ \\
\hline USM 406 & Debaryomyces hansenii & 2.155 & $100 \%$ \\
\hline USM 407 & Candida catenulata & 2.252 & - \\
\hline ULP 412 & Candida krusei & 2.506 & - \\
\hline USM 417 & Pichia guilliermondii & 2.652 & $99 \%$ \\
\hline USM 418 & Candida olivae & - & $100 \%$ \\
\hline ULP 432 & Candida orthopsilosis & - & $99 \%$ \\
\hline USM 433 & Candida catenulata & 2.289 & - \\
\hline USM 434 & Candida catenulata & 2.172 & - \\
\hline USM 436 & Candida catenulata & 2.479 & - \\
\hline USM 440 & Trichosporon asahii & - & $100 \%$ \\
\hline ULP 469 & Candida catenulata & 2.070 & - \\
\hline ULP 470 & Candida catenulata & 2.028 & - \\
\hline ULP 471 & Candida catenulata & 2.283 & - \\
\hline ULP 473 & Candida catenulata & 2.385 & - \\
\hline ULP 475 & Pichia heedii & - & $100 \%$ \\
\hline ULP 476 & Candida krusei & 2.306 & - \\
\hline UED 493 & Candida catenulata & 2.286 & - \\
\hline UED 494 & Rhodotorula mucilaginosa & 2.273 & - \\
\hline UED 495 & Rhodotorula mucilaginosa & 2.267 & - \\
\hline UED 496 & Candida catenulata & 2.190 & - \\
\hline UED 497 & Candida catenulata & 2.165 & - \\
\hline UED 498 & Rhodotorula glutinis & - & $99 \%$ \\
\hline UED 499 & Candida catenulata & 2.377 & - \\
\hline UED 500 & Candida catenulata & 2.378 & - \\
\hline UED 501 & Candida catenulata & 2.240 & - \\
\hline UED 502 & Candida catenulata & 2.323 & - \\
\hline UED 503 & Candida catenulata & 2.337 & - \\
\hline
\end{tabular}




\section{Continued}

\begin{tabular}{|c|c|c|c|}
\hline UED 504 & Candida catenulata & 2.203 & - \\
\hline UED 505 & Candida catenulata & 2.243 & - \\
\hline UJF 805 & Candida krusei & 2.375 & - \\
\hline UJF 809 & Candida rugosa & 2.175 & - \\
\hline UJF 812 & Pichia barkeri & 2.388 & - \\
\hline UJF 814 & Stephanoascus ciferrii & - & $100 \%$ \\
\hline UJF 815 & Pichia fermentans & - & $99 \%$ \\
\hline UJF 817 & Cryptococcus neoformans var. grubii & - & $100 \%$ \\
\hline UJF 820 & Candida humilis & - & $100 \%$ \\
\hline UJF 821 & Pichia fermentans & 2.144 & - \\
\hline UJF 822 & Debaryomyces hansenii & - & $100 \%$ \\
\hline UJF 823 & Candida ethanolica & - & $100 \%$ \\
\hline UJF 824 & Candida humilis & 2.173 & - \\
\hline UJF 825 & Pichia kluyveri & 2.045 & - \\
\hline UJF 826 & Candida sorbosa* & 1.947 & - \\
\hline UJF 827 & Candida sorbosa* & 2.297 & - \\
\hline UJF 829 & Candida ethanolica & - & $99 \%$ \\
\hline UJF 830 & Pichia barkeri & - & $98 \%$ \\
\hline UJF 831 & Rhodotorula mucilaginosa & - & $100 \%$ \\
\hline UJF 832 & Candida krusei & 2.430 & - \\
\hline UJF 833 & Candida humilis & 2.265 & - \\
\hline UJF 834 & Candida ethanolica & 2.122 & - \\
\hline UJF 840 & Pichia kluyveri & - & $99 \%$ \\
\hline UJF 842 & Hanseniaspora guilliermondii & - & $99 \%$ \\
\hline UJF 844 & Candida krusei & 2.542 & - \\
\hline UJF 845 & Candida krusei & 2.474 & - \\
\hline UJF 847 & Candida rugosa & 2.057 & - \\
\hline UJF 848 & Candida krusei & 2.445 & - \\
\hline UJF 849 & Pichia barkeri & 2.080 & - \\
\hline UJF 850 & Candida krusei & 2.278 & - \\
\hline UJF 853 & Candida krusei & 2.081 & - \\
\hline UJF 1428 & Candida catenulata & 2.088 & - \\
\hline UJF 1430 & Meyerozyma guilliermondii & - & $100 \%$ \\
\hline UJF 1432 & Candida catenulata & 1.990 & - \\
\hline UJF 1433 & Trichosporon jirovecii & - & $100 \%$ \\
\hline UJF 1435 & Candida catenulata & 2.136 & - \\
\hline UJF 1438 & Trichosporon jirovecii & 2.553 & - \\
\hline UJF 1439 & Trichosporon jirovecii & 2.764 & - \\
\hline UJF 1441 & Trichosporon montevideense & - & $100 \%$ \\
\hline UJF 1444 & Candida catenulata & 1.925 & - \\
\hline UJF 1445 & Cryptococcus neoformans var. grubii & - & $100 \%$ \\
\hline UJF 1454 & Trichosporon asahii & 2.545 & - \\
\hline UJF 1469 & Cryptococcus neoformans var. grubii & - & $100 \%$ \\
\hline UJF 1470 & Cryptococcus neoformans var. grubii & - & $100 \%$ \\
\hline UJF 1471 & Cryptococcus neoformans var. grubii & - & $100 \%$ \\
\hline UJF 3006 & Rhodotorula mucilaginosa & - & $100 \%$ \\
\hline
\end{tabular}

${ }^{* * *}$ Issatchenkia occidentalis. 
Table 3. Isolates that use n-hexadecane as the sole carbon source.

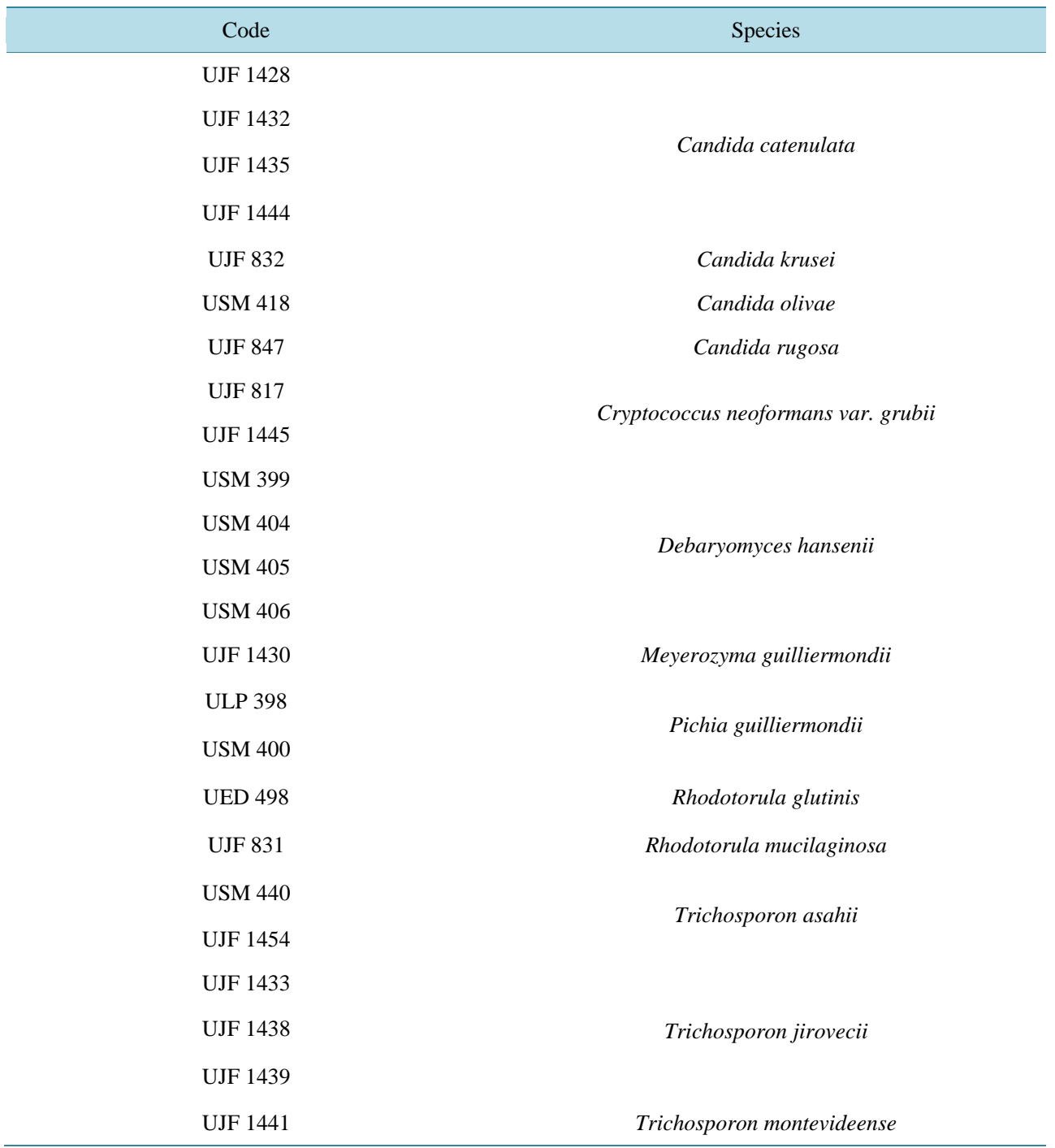

glycerol [39]-[43]. However, other species as $D$. hansenii are well known as food spoilage agents due to its salt and cold tolerance and no reports on its ability to degrade xenobiotic compounds have been reported.

Regarding Basidiomycetes found in this work, in spite of the small number compared to Ascomycetes, most of them (62.5\%) are able to use n-hexadecane as main carbon source. Rhodotorula spp. has been associated to the production of beta-carotene, torulene and enzymes as phenylalanine ammonia lyase. Also, some species were reported as able to convert recalcitrant substrates, as lignin, tannins and pectin [34] [44]-[48]. The genus Cryptococcus and Trichosporon have also been reported as capable of biotransformation of a wide range of substrates as well as xenobiotics substances [34].

\subsection{Selection of $\mathrm{Pb}$ Tolerant Yeasts}

The yeast $S$. cerevisiae has been used to remediate heavy metals due to the fact that its cell wall has the ability to serve as biosorbent [3]. In this work we searched our yeast collection for isolates capable to tolerate $\mathrm{Pb}$ levels higher than those observed by S. cerevisiae strains. We expected that higher tolerance would reflect higher uptake. The disk diffusion method was employed in this experiment in order to overcome $\mathrm{Pb}$ precipitation in liquid culture medium. Disks containing 0.5, 1.0, 2.5 and $5 \mathrm{mg}$ of $\mathrm{Pb}$ were placed in triplicates on plates inoculated with each test isolate and reference strains. Table 4 shows that $S$. cerevisiae BY4742 and BG-1 were inhibited 
Table 4. Pb tolerance of the yeast reference strains and selected isolates from São Paulo Zoo collection.

\begin{tabular}{cc}
\hline Yeast isolate & Pb tolerance level (mg) \\
\hline UJF 502 (C. catenulata) & 2.5 \\
UJF 1441 (T. montevideense) & 5.0 \\
BY4742 (S. cerevisiae S288c) & 1.0 \\
BG-1 (Industrial strain) & 1.0 \\
PE-2 (Industrial strain) & 2.5 \\
CAT-1 (Industrial strain) & 2.5 \\
\hline
\end{tabular}

by $1.0 \mathrm{mg}$, whereas PE-2 and CAT- 1 were inhibited by $2.5 \mathrm{mg}$ of Pb. C. catenulata isolate UJF 502 was no more tolerant than the industrial strains (PE-2 and CAT-1). However, UJF 1441 (T. montevideense) was not inhibited by $5 \mathrm{mg} \mathrm{Pb}$. Therefore, UJF 1441 was considered the most tolerant isolate in the collection and it was selected for further studies. All the other isolate in the collection were inhibited by $1.0 \mathrm{mg}$ and were not pursued further. This result is in accordance to previous reports in the literature, Muñoz et al. [17] reported several yeasts isolated from waste waters, among them a $T$. montevideense and Trichosporon $s p$. which are very tolerant to different heavy metals ( $\mathrm{Pb}, \mathrm{Zn}$ and $\mathrm{Ag}$ ), however those strains were not assayed for heavy metal cell uptake.

\subsection{Pb Uptake by Selected Yeasts}

Isolate UJF 1441 (T. montevideense) and the reference strain CAT-1 were compared regarding their ability to uptake $\mathrm{Pb}$. In many instances the cell wall is responsible for binding the heavy metal but, also, the uptake may dependent upon the microbial metabolism and causes the biotransformation of the metal [49]. To address this question we submitted both strains to UV inactivation and quantified the uptake by Graphite Furnace Atomic Absorption Spectroscopy (GF-AAS) in active and inactive cells. The UV inactivation was chosen since it induces cell death by nucleic acid damage with reduced chance of cell wall damage, as it would if a chemical inducer such as heat was to be used [50]. A survival curve $(0,10,20,30$, and 50 minutes) was performed to define the time of UV irradiation necessary to completely inactivate cells. Although our results showed that 10 minutes of UV-irradiation was enough to inactivate the yeast cells (CAT-1 and UJF 1441) we irradiated the cells for 30 min to assure complete cell inactivation.

The integrity of cell walls was verified by staining with Calcofluor followed by fluorescent microscopy observations. Comparing irradiated and non irradiated cells in both strains there was no difference in calcofluor staining pattern, suggesting the treatment did not change the microscopic characteristics of the yeast cell wall (data not shown).

The graph in Figure 1 show the amount of $\mathrm{Pb}$ precipitated on the cell of active and inactive yeast at various time points (1, 5 and 10 minutes contact of cells and $\mathrm{Pb})$. At all times active or inactive $T$. montevideense cells were capable of significant higher $\mathrm{Pb}$ sorption than $\mathrm{S}$. cerevisiae CAT-1 strain. For both strains the inactive form was more efficient regarding biosorption. Machado et al. [51] reported similar behavior for S. cerevisae from beverage industry when they tested their sorption for $\mathrm{Cu}, \mathrm{Ni}$ and $\mathrm{Zn}$ and concluded that the yeasts inactivated by heat $\left(45^{\circ} \mathrm{C}\right)$ were more efficient for biosorption than active cells.

Biosorption depends exclusively on the sorption sites present in the cell wall structure and in the plasma membrane of the inactive microorganisms; on the contrary bioaccumulation depends upon live cell metabolism [52]. Therefore, the increase sorption of $\mathrm{Pb}^{2+}$ observed in this work by the inactive cells suggests a biosorption mechanism rather than a bioaccumulation. In fact, the Student's t-test indicates that inactive cells have the highest sorption capacity average for both strains evaluated, T. montevideense and CAT-1 (Student's t-test, $p<0.05$ ) when compared to the their active form. Moreover, considering that $T$. montevideense was more tolerant and retained more $\mathrm{Pb}$, a relationship of dependence between tolerance and sorption capacity may established here, which is indicated by the Pearson correlation between these two variables $\left(r^{2}=1\right.$; Student's t-test, $\left.p<0.05\right)$.

It is important to mention that due the precipitation of $\mathrm{Pb}$, the sorption studies were not executed in the culture media, which could favor the retention $\mathrm{Pb}^{2+}$ by the active isolates because of the ideal conditions of growth and development. However, the observed sorption capabilities of the inactive T. montevideense cells (Figure 1), 


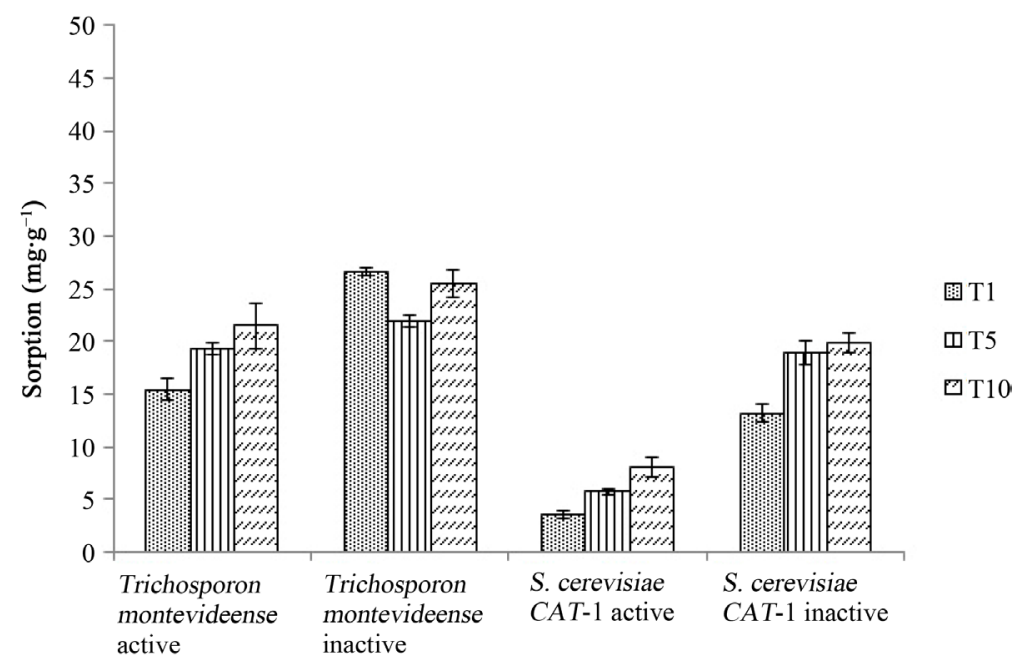

Figure 1. Sorption of $\mathrm{Pb}\left(5000 \mathrm{mg} \cdot \mathrm{L}^{-1}\right)$ for Trichosporon montevideense and S. cerevisiae CAT-1 in different exposure times: 1 minute (T1), 5 minutes (T5) and 10 minutes (T10).

may indicate that this isolate can potentially be used in proccesses involving biosorption. Taken together these results show that 1) yeast collection isolated from São Paulo Zoo Park Compost has a large diversity of yeast species, 2) MALDI-TOF and Biotyper are reliable, easy, time and cost effective method for taxonomic identification, and finally 3) our collection has isolates with great potential for biotechnology applications, mainly related to bioremediation; 23 strains are able to consume a xenobiotic substance, therefore may be applied in polutant removal and inactive T. montevideense is a very robust biosorption agent regarding $\mathrm{Pb}$ uptake and further studies may allow its use in the near future for metal removal from the environment.

\section{Acknowledgements}

The authors would like to acknowledge the staff at São Paulo Zoo Park Compost Unit for the access to the UPCO and their support during sampling and assembling of the compost cells. Dr. Luiz Juliano Neto and Dr. Diego Assis for their assistance with MALDI-TOF. Dr. Marco Aurélio Zezzi for allowing us to use his microwave furnace. Luciana Principal Antunes and Elisângela Dutra Souza for technical assistance. This work was supported with grants from Fundação de Amparo à Pesquisa do Estado de São Paulo (2007/53860-6, 2007/ 50536-3 2009/52030-5, 2011/51298-4, 2011/50870-6) and CAPES MSc student Grant to B. Trama. Strain request should be directed to São Paulo Zoo Park.

\section{References}

[1] Fleishman, E., Blockstein, D.E., Hall, J.A., et al. (2011) Top 40 Priorities for Science to Inform US Conservation and Management Policy. BioScience, 61, 290-300. http://dx.doi.org/10.1525/bio.2011.61.4.9

[2] Zhang, Z., Hou, Z., Yang, C., et al. (2010) Degradation of $n$-Alkanes and Polycyclic Aromatic Hydrocarbons in Petroleum by a Newly Isolated Pseudomonas aeruginosa DQ8. Bioresource Technology, 102, 4111-4116.

http://dx.doi.org/10.1016/j.biortech.2010.12.064

[3] Wang, J.L. and Chen, C. (2006) Biosorption of Heavy Metals by Saccharomyces cerevisiae: A Review. Biotechnology Advances, 24, 427-451. http://dx.doi.org/10.1016/j.biotechadv.2006.03.001

[4] Lessler, M.A. (1988) Lead and Lead Poisoning from Antiquity to Modern Times. The Ohio Journal of Science, 88, 78-84.

[5] Demayo, A., Taylor, C.M., Taylor, K.W., et al. (1982) Toxic Effects of Lead and Lead Compounds on Human Health, Aquatic Life, Wildlife Plants, and Livestock. C R C Critical Reviews in Environmental Control, 12, 257-305. http://dx.doi.org/10.1080/10643388209381698

[6] Moreira, F.R. and Moreira, J.C. (2004) Os efeitos do chumbo sobre o organismo humano e seu significado para a saúde. Revista Panamericana de Salud Pública, 15, 119-129. http://dx.doi.org/10.1590/S1020-49892004000200007

[7] Cui, J. and Zhang, L. (2008) Metallurgical Recovery of Metals from Electronic Waste: A Review. Journal of Hazard- 
ous Materials, 158, 228-256. http://dx.doi.org/10.1016/j.jhazmat.2008.02.001

[8] Song, H., Lia, X., Suna, J., Xua, S. and Hanb, X. (2008) Application of a Magnetotactic Bacterium, Stenotrophomonas sp. to the removal of $\mathrm{Au}(\mathrm{III})$ from Contaminated Wastewater with a Magnetic Separator. Chemosphere, 72, 616-621. http://dx.doi.org/10.1016/j.chemosphere.2008.02.064

[9] Wang, J.L. and Chen, C. (2009) Biosorbents for Heavy Metals Removal and Their Future. Biotechnology Advances, 27, 195-226. http://dx.doi.org/10.1016/j.biotechadv.2008.11.002

[10] Kolvenbach, B.A., Helbling, D.E., Kohler, H.P. and Corvini, P.F. (2014) Emerging Chemicals and the Evolution of Biodegradation Capacities and Pathways in Bacteria. Current Opinion in Biotechnology, 27C, 8-14. http://dx.doi.org/10.1016/j.copbio.2013.08.017

[11] Kumar, A., Bisht, B.S., Joshi, V.D. and Dhewa, T. (2011) Review on Bioremediation of Polluted Environment: A Management Tool. International Journal of Environmental Sciences, 1, 1079-1093.

[12] McGenity, T.J. (2014) Hydrocarbon Biodegradation in Intertidal Wetland Sediments. Current Opinion in Biotechnology, 27, 46-54. http://dx.doi.org/10.1016/j.copbio.2013.10.010

[13] Dursun, A.Y., Uslua, G., Cuci, Y. and Aksub, Z. (2003) Bioaccumulation of Copper(II), Lead(II) and Chromium(VI) by Growing Aspergillus niger. Process Biochemistry, 38, 1647-1651. http://dx.doi.org/10.1016/S0032-9592(02)00075-4

[14] Li, C., Jiang, W., Ma, N., et al. (2014) Bioaccumulation of Cadmium by Growing Zygosaccharomyces rouxii and Saccharomyces cerevisiae. Bioresource Technology, 155, 116-121. http://dx.doi.org/10.1016/j.biortech.2013.12.098

[15] Joo, H.S., Ndegwa, P.M., Shoda, M. and Phae, C.G. (2008) Bioremediation of Oil-Contaminated Soil Using Candida catenulata and Food Waste. Environmental Pollution, 156, 891-896. http://dx.doi.org/10.1016/j.envpol.2008.05.026

[16] Karigar, C.H. and Rao, S.S. (2011) Role of Microbial Enzymes in the Bioremediation of Pollutants: A Review. Enzyme Research, 2011, Article ID: 805187. http://dx.doi.org/10.4061/2011/805187

[17] Muñoz, A.J., Ruiz, E. and Abriouel, H. (2012) Heavy Metal Tolerance of Microorganisms Isolated from Wastewaters: Identification and Evaluation of Its Potential for Biosorption. Chemical Engineering Journal, 210, 325-332. http://dx.doi.org/10.1016/j.cej.2012.09.007

[18] Watanabe, K., Kodoma, Y., Stutsubo, K. and Harayama, S. (2000) Molecular Characterization of Bacterial Populations in Petroleum-Contaminated Groundwater Discharged from Underground Crude Oil Storage Cavities. Applied and Environmental Microbiology, 66, 4803-4809. http://dx.doi.org/10.1128/AEM.66.11.4803-4809.2000

[19] Bitencourt, A.L.V., Vallim, M.A., Maia, D., et al. (2010) Core Sampling Test in Large-Scale Compost Cells for Microorganism Isolation. African Journal of Microbiology Research, 4, 1631-1634.

[20] Dutra, E.S., Pascon, R.C. and Vallim, M.A. (2013) São Paulo Zoo Composting as a Source of Bacteria with Bioremediation Potential. African Journal of Microbiology Research, 7, 5200-5206.

[21] Martins, L.F., Antunes, L.P., Pascon, R.C., et al. (2013) Correction: Metagenomic Analysis of a Tropical Composting Operation at the São Paulo Zoo Park Reveals Diversity of Biomass Degradation Functions and Organisms. PLoS ONE, 8, Article ID: e61928. http://dx.doi.org/10.1371/journal.pone.0061928

[22] Pascon, R.C., Bergamo, R.F., Spinelli, R.X., et al. (2011) Amylolytic Microorganism from São Paulo Zoo Composting: Isolation, Identification and Amylase Production. Enzyme Research, 2011, Article ID: 679624. http://dx.doi.org/10.4061/2011/679624

[23] Basso, L.C., De Amorim, H.V., De Oliveira, A.J. and Lopes, M.L. (2008) Yeast Selection for Fuel Ethanol Production in Brazil. FEMS Yeast Research, 8, 1155-1163. http://dx.doi.org/10.1111/j.1567-1364.2008.00428.x

[24] Freiwald, A. and Sauer, S. (2009) Phylogenetic Classification and Identification of Bacteria by Mass Spectrometry. Nature Protocols, 4, 732-742. http://dx.doi.org/10.1038/nprot.2009.37

[25] Hoffman, C.S. and Winston, F. (1987) A Ten-Minute Preparation from Yeast Efficiently Releases Autonomous Plasmids for Transformation of Escherichia coli. Gene, 57, 267-272. http://dx.doi.org/10.1016/0378-1119(87)90131-4

[26] Rabanal, R.M., Arias, A., Prado, B., Hernández-Pérez, M. and Sánchez-Mateo, C.C. (2002) Antimicrobial Studies on Three Species of Hypericum from the Canary Islands. Journal of Ethnopharmacology, 81, 287-292. http://dx.doi.org/10.1016/S0378-8741(02)00083-1

[27] Darangwa, N., Katskov, D.A. and Heitmann, U. (2013) Making ETAAS Determination Less Dependent on Vaporization Kinetics of the Analytes. South African Journal of Chemistry, 66, 207-215.

[28] Kricka, W., Fitzpatrick, J. and Bond, U. (2014) Metabolic Engineering of Yeasts by Heterologous Enzyme Production for Degradation of Cellulose and Hemicellulose from Biomass: A Perspective. Frontiers in Microbiology, 5, 174.

[29] Nielsen, J., Larsson, C., van Maris, A. and Pronk, J. (2013) Metabolic Engineering of Yeast for Production of Fuels and Chemicals. Current Opinion in Biotechnology, 24, 398-404. http://dx.doi.org/10.1016/j.copbio.2013.03.023

[30] Blackwell, K.J., Singleton, I. and Tobin, J.M. (1995) Metal Cation Uptake by Yeast: A Review. Applied Microbiology 
and Biotechnology, 43, 579-584. http://dx.doi.org/10.1007/BF00164757

[31] Das, N., Vimala, R. and Karthika, P. (2008) Biosorption of Heavy Metals-An Overview. Indian Journal of Biotechnology, 7, 159-169.

[32] Kordialik-Bogacka, E. (2011) Surface Properties of Yeast Cells during Heavy Metal Biosorption. Central European Journal of Chemistry, 9, 348-351. http://dx.doi.org/10.2478/s11532-011-0008-8

[33] Zoghi, A., Khosravi-Darani, K. and Sohrabvandi, S. (2014) Surface Binding of Toxins and Heavy Metals by Probiotics. Mini-Reviews in Medicinal Chemistry, 14, 84-98. http://dx.doi.org/10.2174/1389557513666131211105554

[34] Johnson, E.A. (2013) Biotechnology of Non-Saccharomyces Yeasts-The Basidiomycetes. Applied Microbiology and Biotechnology, 97, 7563-7577. http://dx.doi.org/10.1007/s00253-013-5046-z

[35] Kirk, P.M., Cannon, P.F., David, J.C. and Stalpers, J. (2008) Ainsworth \& Bisby’s Dictionary of the Fungi. CAB International, Wallingford.

[36] Van der Wal, A., Geydan, T.D., Kuyper, T.W. and de Boer, W. (2013) A Thready Affair: Linking Fungal Diversity and Community Dynamics to Terrestrial Decomposition Processes. FEMS Microbiology Reviews, 37, 477-494. http://dx.doi.org/10.1111/1574-6976.12001

[37] Berg, B. and McClaugherty, C. (2008) Plant Litter-Decomposition, Humus Formation, Carbon Sequestration. Springer-Verlag, Berlin, Heidelberg.

[38] Kurtzman, C.P. and Fell, J.W. (2011) The Yeasts: A Taxonomic Study. Elsevier, Amsterdam.

[39] Deivasigamani, C. and Das, N. (2011) Biodegradation of Basic Violet 3 by Candida krusei Isolated from Textile Wastewater. Biodegradation, 22, 1169-1180. http://dx.doi.org/10.1007/s10532-011-9472-2

[40] Domínguez, M.P., Sánchez-Montero, J.M., Sinisterra, J.V. and Alcántara, A.R. (2006) Understanding Candida rugosa Lipases: An Overview. Biotechnology Advances, 24, 180-196. http://dx.doi.org/10.1016/j.biotechadv.2005.09.003

[41] Duarte, E.A.A., Lacerda Jr., G.V., de Oliveira, T.A.S., et al. (2013) Bioprospection of Bacteria and Yeasts from Atlantic Rainforest Soil Capable of Growing in Crude-Glycerol Residues. Genetics and Molecular Research, 12, 4422-4433. http://dx.doi.org/10.4238/2013.October.10.8

[42] El-Latif, H.A., Khan, S., Liu, X., et al. (2006) Application of PCR-DGGE to Analyse the Yeast Population Dynamics in Slurry Reactors during Degradation of Polycyclic Aromatic Hydrocarbons in Weathered Oil. Yeast, 23, 879-887. http://dx.doi.org/10.1002/yea.1401

[43] Romer, M.C., Hammer, E., Cazau, M.C. and Arambarri, A.M. (2002) Isolation and Characterization of Biarylic Structure-Degrading Yeasts: Hydroxylation Potential of Dibenzofuran. Environmental Pollution, 118, 379-382. http://dx.doi.org/10.1016/S0269-7491(01)00290-1

[44] El-Batal, A.I. (2002) Continuous Production of L-Phenylalanine by Rhodotorula glutinis Immobilized Cells Using a Column Reactor. Acta Microbiologica Polonica, 51, 153-169.

[45] Frengova, G.I. and Beshkova, D.M. (2008) Carotenoids from Rhodotorula and Phaffia: Yeasts of Biotechnological Importance. Journal of Industrial Microbiology \& Biotechnology, 36, 163-180. http://dx.doi.org/10.1007/s10295-008-0492-9

[46] Hainal, A.R., Capraru, A.M., Volf, I. and Popa, V.I. (2012) Lignin as a Carbon Source for the Cultivation of Some Rhodotorula Species. Cellulose Chemistry and Technology, 46, 87-96.

[47] Quinn, A.J., Pickup, M.J. and D’Cunha, G.B. (2011) Enzyme Activity Evaluation of Organic Solvent-Treated Phenylalanine Ammonia Lyase. Biotechnology Progress, 27, 1554-1560. http://dx.doi.org/10.1002/btpr.687

[48] Taskin, M. (2013) Co-Production of Tannase and Pectinase by Free and Immobilized Cells of the Yeast Rhodotorula glutinis MP-10 Isolated from Tannin-Rich Persimmon (Diospyros kaki L.) Fruits. Bioprocess and Biosystems Engineering, 36, 165-172. http://dx.doi.org/10.1007/s00449-012-0771-8

[49] Ilhan, S., Cabuk, A., Filik, C. and Calikan, F. (2004) Effect of Pretreatment on Biosorption of Heavy Metals by Fungal Biomass. Trakya University Journal of Social Science, 5, 11-17.

[50] Del Carratore, R., Croce, C.D., Simili, M., et al. (2002) Cell Cycle and Morphological Alterations as Indicative of Apoptosis Promoted by UV Irradiation in S. cerevisiae. Mutation Research, 513, 183-191. http://dx.doi.org/10.1016/S1383-5718(01)00310-2

[51] Machado, M.D., Santos, M.S., Gouveia, C., Soares, H.M. and Soares, E.V. (2009) Removal of Heavy Metals Using a Brewer's Yeast Strain of Saccharomyces cerevisiae: The Flocculation as a Separation Process. Bioresources Technology, 99, 2107-2115. http://dx.doi.org/10.1016/j.biortech.2007.05.047

[52] Chojnacka, H. (2010) Biosorption and Bioaccumulation-The Prospects for Practical Applications. Environment International, 36, 299-307. http://dx.doi.org/10.1016/j.envint.2009.12.001

[53] Valente, P., Ramos, J.P. and Leoncini, O. (1999) Sequencing as a Tool in Yeast Molecular Taxonomy. Canadian Journal of Microbiology, 45, 949-958. http://dx.doi.org/10.1139/w99-094 
Scientific Research Publishing (SCIRP) is one of the largest Open Access journal publishers. It is currently publishing more than 200 open access, online, peer-reviewed journals covering a wide range of academic disciplines. SCIRP serves the worldwide academic communities and contributes to the progress and application of science with its publication.

Other selected journals from SCIRP are listed as below. Submit your manuscript to us via either submit@scirp.org or Online Submission Portal.
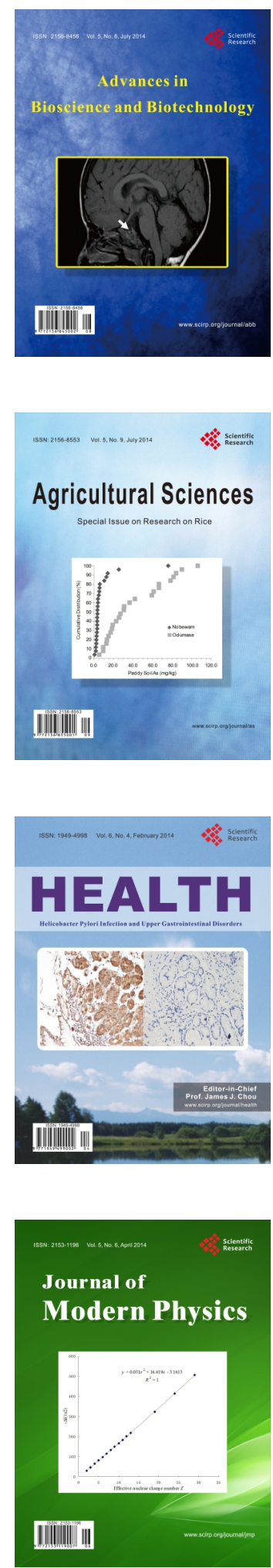
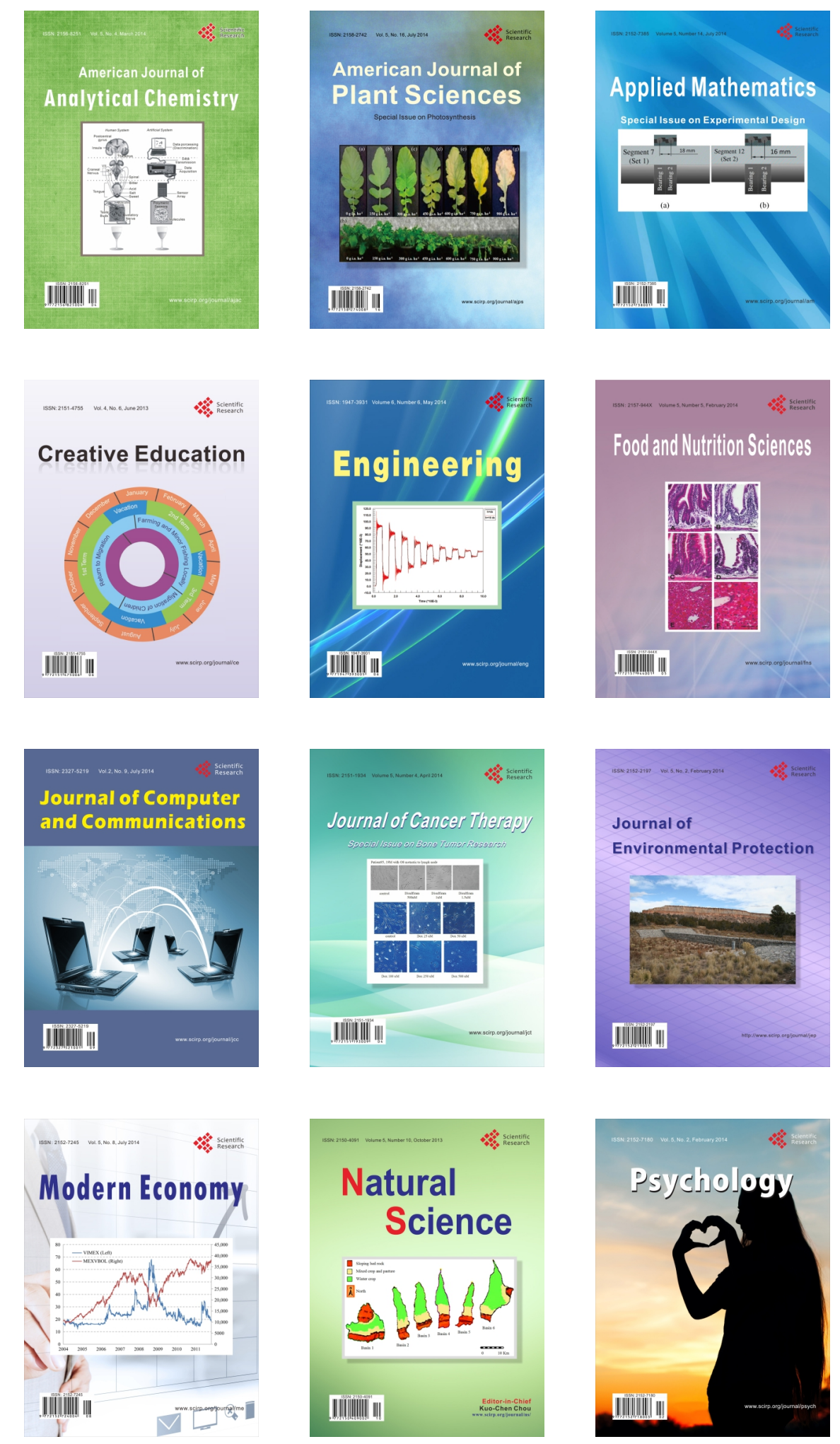